REVIEW

\title{
Dust concentrations and respiratory risks in coalminers: key risk estimates from the British Pneumoconiosis Field Research
}

\author{
C A Soutar, J F Hurley, B G Miller, H A Cowie, D Buchanan
}

Occup Environ Med 2004;61:477-481. doi: 10.1136/oem.2002.006726

To help inform the setting of dust control standards in coalmines, this brief review summarises the most recent and reliable exposure-response relations, for damaging respiratory effects, derived from the Pneumoconiosis Field Research (PFR). Collecting data over 38 years in the British coal industry, this was a programme of prospective research on the respiratory health of coal miners, characterised by regular health surveys and detailed measurements of dust and silica concentrations in the workplace. Exposure-response relations are presented for coal workers' simple pneumoconiosis category II, progressive massive fibrosis, defined deficits of lung function $\left(F E V_{1}\right)$, and category II silicosis. This simplified overview provides a guide to the most recent and most reliable estimates from the PFR of dust-related risks of substantial pulmonary disease, and to the magnitude of the effects. Control of dust sufficient to prevent category II simple pneumoconiosis should prevent most cases of progressive massive fibrosis and most dust related large lung function deficits. Where the dust contains high proportions of silica, control to low levels is essential, and even quite brief excursions of silica to high levels must be avoided.

See end of article for authors' affiliations

Correspondence to: $\operatorname{Dr} C A$ Soutar, Institute of Occupational Medicine, Research Park North, Riccarton, Edinburgh EH14 4AP, UK: colin.soutar@iomhq.org.uk

Accepted

8 September 2003
$\mathrm{T}$ he British Pneumoconiosis Field Research (PFR), a prospective exposure-response epidemiological study, was conducted by the Institute of Occupational Medicine, on behalf of the British coal industry, between 1953 and 1991. Supplementary studies and data analysis continue to this day. Its aim was "... to find out how much and what kinds of dust cause pneumoconiosis, and to establish what environmental conditions should be maintained if mine workers are not to be disabled by the dust they breathe ...".

To inform setting and implementation of dust control limits, this review represents a brief summary of the most recent and most reliable estimates from the research of the quantitative dust related risks of damaging respiratory health effects. Supporting information on the research methods is given in the Appendix, and additional details may be found in the referenced source papers and reports.

\section{METHODS}

The PFR initially included 25, then 24, collieries, chosen to represent the range of conditions in British coal mines at the time. After the first 10 years of the research, 10 collieries continued in the study to 1977. Data collection continued in one colliery until 1980, with a follow up medical survey in 1991, because unusual airborne quartz concentrations were encountered.

Medical examinations were conducted on miners employed at these collieries every five years. A uniquely detailed prospective sampling strategy was implemented throughout the research, comprising measurements of respirable dust and quartz concentrations for numerous occupational groups in each colliery. Frequencies of measurements ranged from three monthly for surface workers up to 50 annually for high exposed groups. Concentrations were linked to occupational histories, in order to estimate a cumulative lifetime exposure for each man. Average concentrations, given as examples in this paper, are calculated by dividing cumulative exposure by total time worked.

\section{OVERVIEW OF EXPOSURE-RESPONSE RELATIONS}

Exposure-response relations have been established for the effects of mixed respirable coal mine dust on simple pneumoconiosis, complicated pneumoconiosis (progressive massive fibrosis), symptoms of chronic bronchitis, and clinically important lung function deficits, and for the effects of free crystalline silica on silicosis.

\section{Simple pneumoconiosis and progressive massive fibrosis}

The most reliable estimates of risks of coal workers' simple pneumoconiosis (CWSP) and progressive massive fibrosis (PMF) were based on about 50000 observations of men at risk during 25 years of the research..$^{2-4}$ Methods are summarised in the Appendix. Risk of PMF is positively related to dust exposure, age, stature (tall for weight), the presence of CWSP, and the proportion of carbon in the coal. In this review risks have been expressed for coal that is $86.2 \%$ carbon, and the estimates have been adjusted for the estimated prevalence of CWSP.

Abbreviations: CWSP, coal workers' simple pneumoconiosis; FEV, forced expiratory volume; PFR, Pneumoconiosis Field Research; PMF, progressive massive fibrosis 
Figure 1 shows the risks at age 58 in comparison with average respirable dust concentration over a working lifetime of 40 years. Risks of an attack of PMF rise from about $0.8 \%$ at $1.5 \mathrm{mg} . \mathrm{m}^{-3}$ to about $5 \%$ at $6 \mathrm{mg} . \mathrm{m}^{-3}$. Risks of category II CWSP are higher, rising from about $1.5 \%$ at a mean concentration of $1.5 \mathrm{mg} \cdot \mathrm{m}^{-3}$ to about $9 \%$ at $6 \mathrm{mg} \cdot \mathrm{m}^{-3}$.

\section{Lung function}

The lung function of miners can be affected adversely by dust exposure, irrespective of the presence of pneumoconiosis. ${ }^{5} \mathrm{~A}$ study of 7000 miners $^{6}$ defined clinically important deficits of forced expired volume in one second $\left(\mathrm{FEV}_{1}\right)$ by comparisons with reported symptoms of breathlessness, and then studied the dust related risk of having these deficits. A threefold increase in the odds of reporting "walking slower than other people on level ground because of their chest" was associated on average with a 0.993 litre $\mathrm{FEV}_{1}$ deficit from predicted. This was defined as a clinically important lung function deficit, and is a substantial deficit by any standard.

Figure 1 illustrates the risks, for non-smokers and smokers, of having a deficit of at least this magnitude at age 60 in relation to exposures to average dust concentrations experienced over a 35 year working life. For non-smokers, risks are about $10 \%$ for zero dust concentrations, rising to about $19 \%$ for an average concentration of $6 \mathrm{mg} \cdot \mathrm{m}^{-3}$. For smokers, risks were $22 \%$ and about $36 \%$ respectively.

The slope representing dust related increments in risk is similar to that for category II pneumoconiosis, so reductions in dust levels to protect against pneumoconiosis would protect a similar number of men from this lung function deficit.

Smaller deficits of lung function were also examined, showing steeper incremental slopes. For example, a twofold increase in risk of reporting breathlessness was associated with a $627 \mathrm{ml}$ deficit of $\mathrm{FEV}_{1}$. The risks of this deficit in nonsmokers were about $25 \%$ at zero dust concentration, and nearly $40 \%$ at a mean concentration of $6 \mathrm{mg} \cdot \mathrm{m}^{-3}$. Comparable figures for smokers were $44 \%$ and nearly $60 \%$ respectively. A 1.5 -fold increase in risk of reporting breathlessness was associated with a $367 \mathrm{ml}$ deficit of $\mathrm{FEV}_{1}$. The risks of this deficit in non-smokers were about $41 \%$ at zero dust concentration, and over $55 \%$ at a mean concentration of $6 \mathrm{mg} \cdot \mathrm{m}^{-3}$. Comparable figures for smokers were $62 \%$ and about $75 \%$ respectively.

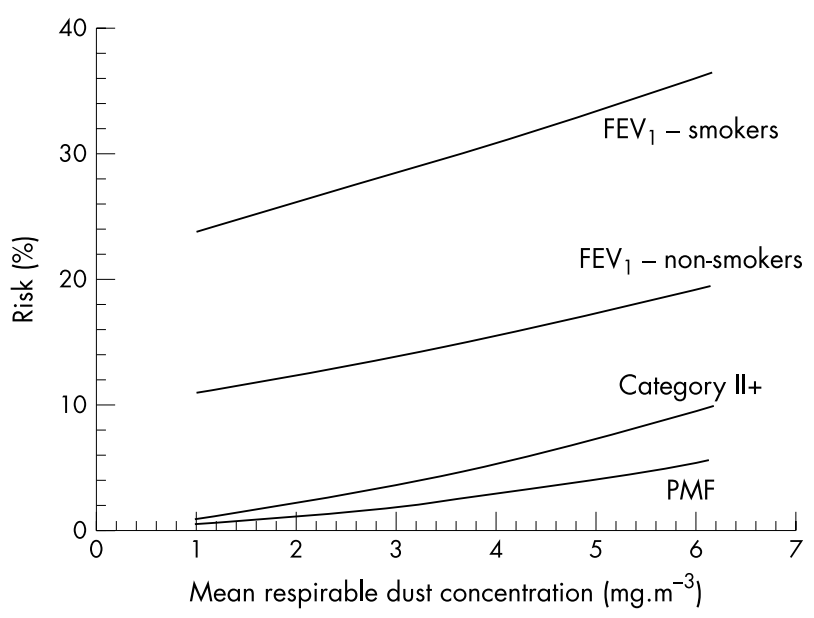

Figure 1 Risks at age 58-60 after 35-40 working years of: PMF; category $\mathrm{ll}+$ simple pneumoconiosis; $993 \mathrm{ml}$ deficit of $\mathrm{FEV}_{1}$ in nonsmokers; $993 \mathrm{ml}$ deficit of $\mathrm{FEV}_{1}$ in smokers.

\section{Silicosis}

In most British mines, free crystalline silica (quartz) concentrations in the dust are generally less than $10 \%,{ }^{7}$ and quartz has no consistent influence on risks of pneumoconiosis after the effects of mixed dust have been taken into account. ${ }^{8}$ By contrast, in a few collieries, high quartz concentrations were associated with rapid progression of CWSP and the development of PMF. ${ }^{9}$ In one colliery in the research, adverse mining conditions resulted in unusually high quartz concentrations during the late 1960s and 1970s. Both the proportions of quartz in the respirable dust, and the absolute concentrations of quartz, were unusually high (sometimes over $20-30 \%$, and with concentrations up to 2 , 3 , or $4 \mathrm{mg} \cdot \mathrm{m}^{-3}$ or higher). Subsequently cases of radiological abnormality developed with unusual frequency and rates of progression. ${ }^{10}$ Risks of radiological abnormalities 10 years after the colliery closed in 1981 were associated more strongly with exposure to quartz than to mixed dust, and the analyses indicated high risks at low concentrations. ${ }^{11}$

In previous work, and in the results described so far in this paper, exposure has been expressed as concentration multiplied by time. This assumes that concentration has little influence on risk other than its contribution to cumulative exposure. It is plausible in the case of an agent like quartz that causes inflammation, and delays its own clearance from the lung, that high concentrations for limited periods might cause more damage than lower concentrations experienced over longer periods.

The fit was examined between different expressions of exposure and observed prevalence of radiographic abnormality. ${ }^{12}$ Methods are summarised in the Appendix. The exposure measure of best fit was the square of concentration multiplied by time. This is consistent with high concentrations causing disproportionately severe harm.

A good, simple, representation of the risks was given by a statistical model in which one exposure measure was confined to silica concentrations less than $2 \mathrm{mg} . \mathrm{m}^{-3}$, and another to concentrations greater than $2 \mathrm{mg} \cdot \mathrm{m}^{-3}$. Figure 2 shows the risk estimates from this model, for category II silicosis. The risks for cumulative exposures to concentrations greater than $2 \mathrm{mg} \cdot \mathrm{m}^{-3}$ are very much higher than for exposures to concentrations less than $2 \mathrm{mg} \cdot \mathrm{m}^{-3}$.

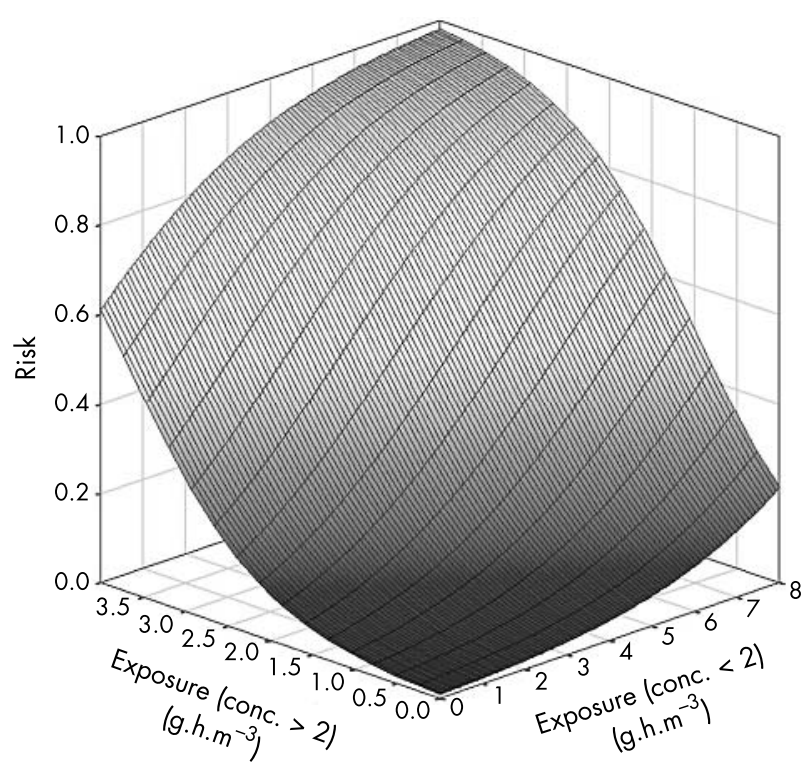

Figure 2 Risks of category $\mathrm{ll}+$ silicosis in relation to cumulative exposures to silica concentrations below, and above, $2 \mathrm{mg} \cdot \mathrm{m}^{-3}$. 
Main messages

- Dust control sufficient to prevent simple pneumoconiosis category II should prevent most dust related large functional losses, and most cases of PMF.

- Where the dust contains high proportions of silica, control to low levels is essential, and even quite brief excursions of silica to high levels must be avoided.

- Risk estimates for these responses are given for a range of exposures.

Even a few months' exposure to concentrations over $2 \mathrm{mg} \cdot \mathrm{m}^{-3}$ results in a greatly increased risk; for example, four months' exposure to $4 \mathrm{mg} \cdot \mathrm{m}^{-3}$ gives a risk of $15 \%$, and this risk would be greatly increased if chronic exposure to lower concentrations had also been experienced.

Clearly it is imperative that even quite brief excursions of quartz concentration to high levels are prevented.

Figure 3 shows the risks of silicosis compared with average concentrations, assuming all are in the low range, experienced over a 15 year period, with a 15 year subsequent follow up period. For example, risks are estimated to be $2.5 \%$ at an average concentration of $0.1 \mathrm{mg} \cdot \mathrm{m}^{-3}$, rising to $20 \%$ at $0.3 \mathrm{mg} \cdot \mathrm{m}^{-3}$.

The lowest exposure of any category II case was equivalent to a concentration averaged over 12 years of $0.1 \mathrm{mg} \cdot \mathrm{m}^{-3}$. Below this, extrapolation indicated that at an average concentration of $0.02 \mathrm{mg} \cdot \mathrm{m}^{-3}$, the risks are estimated at $1 \%$, possibly not significantly different from zero $(0.8 \%$ risk is estimated at zero exposure). Estimated risks reach 2\% between 0.06 and $0.08 \mathrm{mg} . \mathrm{m}^{-3}$.

\section{DISCUSSION}

This simplified overview provides a guide to the most recent and most reliable estimates from the PFR of dust related risks of substantial pulmonary disease, and to the magnitude of the effects. Those seeking more detail, or who plan to use the information for dust control purposes, will wish to study the quoted sources, to grasp the breadth and complexity of the data.

\section{Reliability of the risk estimates}

PFR estimates of the risks of coal workers' simple pneumoconiosis (CWSP) informed the setting of the current British

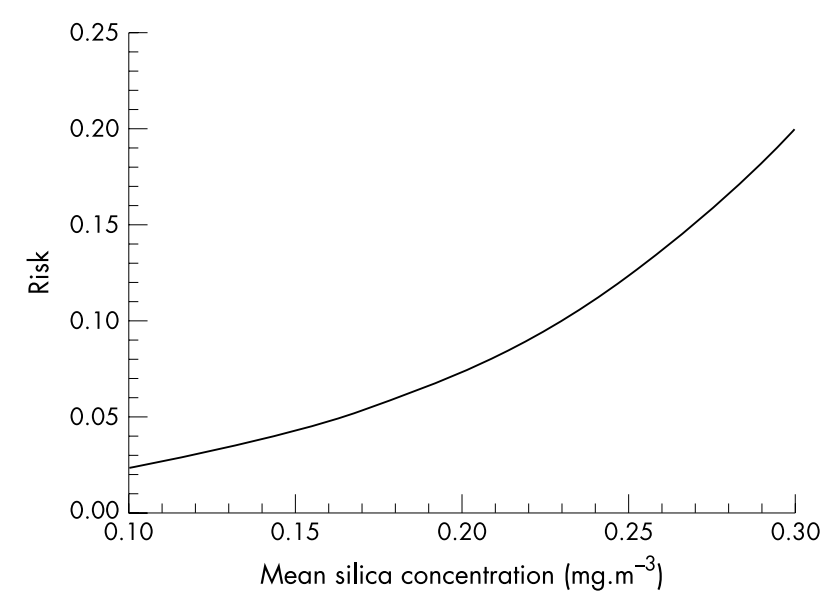

Figure 3 Risks for category II silicosis in relation to respirable silica concentration $\left(<2 \mathrm{mg} \cdot \mathrm{m}^{-3}\right)$ averaged over 15 years.

\section{Policy implications}

- Intended to inform the setting of dust control standards in coalmines, this summary paper is a guide to the key risk estimates from the British Pneumoconiosis Field Research.

- Those seeking more detail, or who plan to use the information for dust control purposes, will wish to study the quoted sources, to grasp the breadth of the data, and their complexities.

statutory dust control limits that have been highly effective in reducing the incidence of pneumoconiosis. ${ }^{13}$

Men from all the British coalfields were included, representing a wide variety of mining conditions. The estimates of exposure are based on unusually detailed work history records and an unusually intensive long term programme of environmental sampling. Dust concentrations in the period before the research began (ISP0) (and for time spent at non-research collieries during the research) were assumed to have been the same as those measured in the first 10 years of the research. Should this have underestimated exposures, the resulting estimated exposure specific risks would have been exaggerated. This possibility cannot be completely excluded since the risks at low dust concentrations estimated from an earlier study ${ }^{14}$ that did not use ISP0 exposures were slightly lower than those estimated from a later study that did. $^{2}$ The differences could have been influenced by different methodologies and further data quality improvements, though. Apart from this, these estimates are considered to overestimate very slightly the risks at low concentrations. ${ }^{15}$

The risks of simple coalworkers' pneumoconiosis and progressive massive fibrosis have been expressed for coal containing $86 \%$ carbon. Risks would be slightly higher for higher carbon proportions, and vice versa. ${ }^{23}$

The risks of silicosis described here are based on highly detailed exposure measurements, and are consequently reliable. If the effects of silica vary according to the conditions of exposure, these risks are probably towards the high end of the risk spectrum, since the silica was freshly fractured from massive sandstone, and not derived from dirt bands where the quartz grains are aged and accompanied by clay minerals. ${ }^{12}$

The reader will note that silicosis and PMF can appear or progress, and lung function continue to decline, after dust exposure has ceased. While our risk estimates are expressed for 58-60 year old men, these conditions may progress further during retirement. Note also that the silicosis risks are based on a 15 year period of exposure, and 15 year subsequent follow up. A longer period of follow up might identify further cases, though we would expect most of the eventual cases to have shown some signs of abnormality by now.

The estimated risks of lung function deficits fitted the observed data well. ${ }^{6}$ Some $10 \%$ of non-smokers at age 60 and with zero dust exposure are estimated to have a $993 \mathrm{ml}$ deficit of $\mathrm{FEV}_{1}$. This includes any subjects with nonoccupational disease (for example, asthma, past tuberculosis, bronchiectasis). For comparison, calculations from the quoted standard deviation in summary general population statistics ${ }^{16}$ indicate that about $2.5 \%$ of adult men have an $\mathrm{FEV}_{1}$ deficit of about 1 litre, not strongly influenced by age in healthy non-smokers. ${ }^{17}$ However, many of the studies on which these estimates are based excluded subjects with 
respiratory symptoms, thus presumably reducing the numbers of subjects with abnormal lung function.

While we have shown that brief exposures to high concentrations of silica have an important influence on risk of silicosis, this has not been examined in relation to the influence of mixed dust on pneumoconiosis or lung function. It would be interesting to do so.

\section{ACKNOWLEDGEMENTS}

We thank our many colleagues, past and present, who played important parts in this extended research programme; also the miners who took part, and the National Coal Board, subsequently British Coal, and the EU, HSE, and NIOSH, who funded the work.

\section{Authors' affiliations \\ C A Soutar, J F Hurley, B G Miller, H A Cowie, D Buchanan, Institute of Occupational Medicine, Edinburgh, UK \\ Supplemented text of a presentation to the China International Forum on Work Safety, Beijing, October 2002 \\ The Institute of Occupational Medicine Reports and Technical Memoranda listed in the reference list can be obtained from the British Library, or from the Technical Information Officer, Institute of Occupational Medicine, Research Park North, Riccarton, Edinburgh EH14 4AP, UK; iom@iomhq.org.uk}

\section{APPENDIX}

\section{THE DESIGN OF THE PNEUMOCONIOSIS FIELD RESEARCH (PFR)}

Structurally the PFR consisted of a series of cross-sectional studies of the respiratory health of currently employed (and in some studies ex-) miners, linked to a continuous and detailed prospective programme of measurements of dust exposure. Study of the data continues to provide answers to important questions, concerning coalminers and more generally.

\section{Medical surveys}

Six rounds of medical surveys, at approximately five yearly intervals, were conducted between 1953 and 1977. Of the 25 pits included in the first round (PFRl, from 1953 to 1958), 24 were included again in PFR2 (1957 to 1963), and PFR3 (1963 to 1968; end of first phase). For PFR4 (1970 to 1973) and PFR5 (1973 to 1977), the number of collieries was reduced to 10 (second phase). Two collieries were included in PFR6 in 1977, after which the regular surveys stopped. Data collection (including medical surveys in 1978 and 1991) continued in one colliery where unusual quartz concentrations had occurred.

\section{Work histories}

The men at each colliery were allocated to occupational groups based on place of work and occupation, revised as mining conditions and practice changed. Weekly records for every man in the occupational groups were supplemented by medical survey interviews on other coalmining experience.

At the colliery with unusual quartz concentrations, time worked was recorded as hours within each occupational group, from 1954 until closure in 1981, but in much more detail after 1974 .

\section{Dust measurements}

Dust concentrations were monitored using sampling instruments close to individual men ("instrument carriers") throughout selected working shifts. On this basis the average concentrations of respirable coalmine dust were determined for all occupational groups and every five year inter-medical survey period (ISP1, 2, 3, 4, and 5). The standard thermal precipitator ${ }^{18}$ was used in the first phase of the research. Its dust sampling characteristics were related, during a series of side-by-side instrument comparisons ${ }^{7}$ to those of the MRE gravimetric sampler ${ }^{19}$ that was used subsequently. The earlier particle count measurements were re-expressed in equivalent gravimetric units. It was assumed that dust concentrations before the research began (ISP0) were similar to those experienced during the following 10 years.

Respirable dust samples were pooled within occupational groups to enable measurement of the quartz content. In the colliery with unusual quartz concentrations, quarterly mean quartz concentrations were available for each occupational group from 1968.

\section{Dust exposures}

The exposures of individuals to respirable coalmine dust in any ISP were calculated by forming the products of hours worked (in occupational groups) with the corresponding average dust concentrations, and summing these products over all groups in which the man had worked over the period.

\section{Medical examinations}

At each examination a full sized postero-anterior chest radiograph was taken. They were read for clinical purposes for the studies reported here during the first phase of the research by at least two of four medical officers experienced in the classification of the appearances of pneumoconiosis. ${ }^{20}$ Subsequent radiographs were interpreted by any one of five or six medical officers. Radiographs for the study of silicosis were read in a special reading trial by a panel of three expert medical readers according to ILO $1980 .^{21}$

At the second and subsequent surveys a respiratory symptoms and smoking questionnaire ${ }^{22}$ was administered and lung function measured by simple spirometry. ${ }^{5}$

\section{POPULATION SAMPLES, STUDY DESIGNS, AND BROAD ANALYTICAL APPROACHES \\ Simple pneumoconiosis and PMF}

The analyses ${ }^{23}$ of risks of simple pneumoconiosis and PMF were based on observations on about 30000 miners who attended two or more successive medical surveys between 1953 and 1978 (PFRl to PFR5/6). Data from 52264 approximately five year periods were used to derive estimates of risk of developing PMF over a 40 year working lifetime.

Firstly, general estimates were made of the probabilities of change in radiological category over five year periods, and of how these probabilities depend also on age, dust exposure at initial survey, and the carbon content of the coal. Secondly, the experience of a hypothetical mining population was followed through to identify the values of age, cumulative dust exposure, and percentage carbon in the coal experienced by men at the start of each five year period. Thirdly, the various combinations of age, exposure, and percentage carbon in the population at the start of each five year period were linked together with the general estimates of age, exposure, and carbon specific risks of radiological change, to give specific estimates of how various subgroups progressed or regressed in each five year period. Finally, the experience of the entire mining population was considered through eight successive five year risk periods, estimating the changes in radiological status in each interval and taking these attained prevalences as starting points for the succeeding risk period.

\section{Lung function}

The cross-sectional analyses of lung function were based on 7188 of the miners who attended nine of the collieries in the PFR5 medical survey. ${ }^{6}$ Firstly the association between presence or absence of self-reported breathlessness and age, smoking habit, and $\mathrm{FEV}_{1}$ was quantified using logistic regression methods. The results enabled the identification of $\mathrm{FEV}_{1}$ deficits from predicted that were associated with selected values of increased risk (odds ratios) of reporting 
breathlessness. The selected values were factors of 1.5, 2, and 3 , and the associated $\mathrm{FEV}_{1}$ deficits were found to be -0.367 , -0.627 , and -0.993 litres respectively.

Secondly, the association between $\mathrm{FEV}_{1}$ and exposure to respirable dust up to PFR5, adjusted for age, physique, and smoking habit, was examined by multiple linear regression, and this model was used to calculate the estimated values of $\mathrm{FEV}_{1}$ associated with various levels of cumulative dust exposure. Separate estimated values were calculated for different age and smoking groups as necessary. Assuming that the distribution of levels around this estimate followed a Normal distribution, it was possible to estimate the probability that any individual would have an $\mathrm{FEV}_{1}$ below any specified value, including the three values derived from the earlier analyses.

\section{Silicosis}

The analysis ${ }^{12}$ was based on 549 men who attended the 1991 follow up survey at this colliery, out of a study population of 1416 who had attended at least one of the surveys in 1970, 1974, and 1978.

A series of general exposure indices (GEI) to quartz were derived with parameters that described the influence of lung residence time and "peakedness" of exposures. Each GEI was formed by the sum of the products of time, concentration, and elapsed time since exposure for each occupational group, with concentration and elapsed time raised to different powers for each GEI.

The strength of statistical associations between the profusion of small opacities at follow up survey and a series of candidate GEIs were compared, using polychotomous logistic regression models. The indices for concentration were highly significant within both the $<50$ and $50-75$ age groups, with the largest deviances in the latter group. In the $<50$ group, deviances for GEIs with a power of concentration less than 1 were highest, whereas for the 50-75 group powers greater than 1 gave the highest deviances, the highest being the square of the concentration. In the $75+$ group, however, GEI estimated effects were very low and non-significant. In all age groups little influence of elapsed time was shown, probably because there was a narrow range of times, since men had tended to experience their high exposures, and were followed up, at similar calendar times.

The form of the above statistical model is inconvenient for predictions of risk based on hypothetical exposures. An alternative model comprising only two explanatory quartz exposure variables fitted well the relations with radiographic abnormality. The two quartz variables were cumulative exposure to concentrations greater than, or less than $2 \mathrm{mg} \cdot \mathrm{m}^{-3}$. This model was used to predict risks in men aged 50-75, since they had experienced the widest range of quartz concentrations, and showed the strongest exposure-response relations.

To enable the summary comparisons in this paper, risk estimates have been derived from the summary data presented in the source papers either directly or with a cautious degree of approximation or extrapolation. The estimates are in some cases expressed in relation to slightly different limits of age and working lifetime. The authors of the source papers made these choices based on the characteristics of the populations and information requirements at the time. We have not attempted to rework the estimates for greater consistency, but suggest that these relatively trivial differences can be ignored for the purposes of this overview.

\section{REFERENCES}

1 Fay JWJ, Rae S. The Pneumoconiosis Field Research of the National Coal Board. Ann Occup Hyg 1959;1:149-61.

2 Hurley JF, Maclaren WM. Dust-related risks of changes in coalminers over a working life: report on work commissioned by NIOSH, Technical Memorandum Series. TM/87/09. Edinburgh: Institute of Occupational Medicine, 1987

3 Hurley JF, Maclaren WM, Alexander WP, et al. Factors influencing the occurrence of progressive massive fibrosis in British coalminers, Technical Memorandum. TM/84/2. Edinburgh: Institute of Occupational Medicine, 1984.

4 Hurley JF, Maclaren WM. Factors influencing the occurrence of progressive massive fibrosis (PMF) in miners and exminers. In: Dodgson J, McCallum RI Bailey MR, Fisher DR, eds. Inhaled particles VI. Oxford: Pergamon Press, 1988.

5 Rogan JM, Atffield MD, Jacobsen M, et al. Role of dust in the working environment in development of chronic bronchitis in British coalminers. Br J Ind Med 1973;30:217-26.

6 Cowie HA, Miller BG, Soutar CA. Dust-related clinically relevant lung functional defects, Research Report. TM/99/06. Edinburgh: Institute of Occupational Medicine, 1999.

7 Dodgson J, Hadden GG, Jones CO, et al. Characteristics of the airborne dust in British coal mines. In: Walton WH, ed. Inhaled particles III. Old Woking, Surrey: Unwin Bros, 1971.

8 Walton WH, Dodgson J, Hadden GG, et al. The effect of quartz and other non-coal dusts in coalworkers' pneumoconiosis. In: Walton WH, ed. Inhaled particles IV. Oxford: Pergamon Press, 1977.

9 Jacobsen M, Maclaren WM. Unusual pulmonary observations and exposure to coal mine dust: a case-control study. In: Walton WH, ed. Inhaled particles $V$. Oxford: Pergamon Press, 1982.

10 Seaton A, Dick JA, Dodgson J, et al. Quartz and pneumoconiosis in coalminers. Lancet $1981 ;$;i: $1272-5$.

11 Miller BG, Hagen S, Love RG, et al. Risks of silicosis in coalworkers exposed to unusual concentrations of respirable quartz. Occup Environ Med 1998;55:52-8.

12 Buchanan D, Miller BG, Soutar CA. Quantitative relations between exposure to respirable quartz and risk of silicosis. Occup Environ Med 2003;60:159-64

13 Afacan AS, Scarisbrick DA. Respiratory health surveillance in the UK coal mining industry. International Mining and Minerals 2001:3-7.

14 Jacobsen $\mathrm{M}$, Rae S, Walton $\mathrm{WH}$, et al. The relation between pneumoconiosis and dust exposure in British coalminers. In: Walton WH, ed. Inhaled particles III. Old Woking, Surrey: Unwin, 1971.

15 Hurley JF, Kenny L, Miller BG. Health impact estimates of dust-related disease in UK coal miners: methodological and practical issues. In: Ogden $\mathrm{TL}_{\text {, }}$ Donaldsen K, Cherry NM, eds. Inhaled particles IX. Oxford: Oxford University Press, 2002.

16 Quanjer PH, ed. Standardisation of lung function tests. Report of working party. Bulletin Europeen de Physiopathologie Respiratoire 1983;19(suppl 5) .

17 Schoenberg JB, Beck GJ, Bouhuys A. Growth and decay of pulmonary function in healthy blacks and whites. Respir Physiol 1978;33:367-93.

18 Watson HH. The thermal precipitator. Transactions of the Institute of Mining and Metallurgy 1936;46:155-240.

19 Dunmore JH, Hamilton RJ, Smith DSG. An instrument for the sampling of respirable dust for subsequent gravimetric assessment. Journal of Scientific Instruments 1964:41:669-72.

20 International Labour Office. Meeting of experts on the international classification of ragiographs of the pneumoconioses. Occupational Safety and Health 9. Geneva: International Labour Office, 1959.

21 ILO. Guidelines for the use of the ILO international classification of radiographs of pneumoconiosis, revised edition. ILO, 1980.

22 Rae S, Walker DD, Attfield MD. Chronic bronchitis and dust exposure in British coalminers. In: Walton WH, ed. Inhaled particles III. Old Woking, Surrey: Unwin, 1971 